Inventory about the last four continental local pig breeds : results obtained after years of application of the conservation programme
introduced by I.N.R.A. and I.T.P.

C. TEXIER *, M. LUQUET *, A. BOUBY *, M. MOLENAT **, J. HOERTER $* * *$, G. SALLIOT $* * * *$ A. TOUZANNE ***;*;

* I.T.P., 149, rue de Bercy, 75595 Paris Cedex 12

***I.N.R.A., Station de Génétique quantitative et appliquée, 78350 Jouy-en-Josas

*** E.D.E. de la Corrèze, 12, place Marcel-Brigoulex, B.P. 44, 19002 Tulle Cedex

*:*: E.D.E. de la Manche, Maison de l'Agriculture, avenue de Paris, B.P. 74, 50001 Saint-Lo Cedex

*****:E.D.E. des Hautes-Pyrénées, 22, place du Foirail, 65000 Tarbes

France

Owing to an inquiry conducted by I.T.P. in 1981 it was possible to enumerate the last breeding animals belonging to the four local pig breeds still existing in France.

Since 3 years these Norman, Limousin, Gascon and Basque populations have been concerned by a conservation programme introduced by the I.N.R.A. and I.T.P.

Last census results indicate the existence of 15 boars and 199 sows in the Norman, 8 and 68 in the Limousin, 15 and 82 in the Gascon and 8 and 69 in the Basque breed.

This programme applied in 1982 and 1983 to 4 pig breed populations (The Norman breed population represented 50 p. 100) led to :

- rearing of 105 young replacer boars,

- freezing of 180 semen doses,

- creation of 12 herds as a "breeding animal stock" outside the 3 traditional production areas.

Through annual visits to the different farmers, a herd book was updated for each breed by I.T.P. and the use of service boars controlled.

Results registered in 1982 give some information about reproduction in each breed (164 matings recorded and 85 litters controlled representing 9.9 piglets born per litter for the Norman breed).

Results obtained with the other three breeds were 102, 86, 9.4, respectively for Limousin, 41, 43, 8.6 for Gascon and $51,46,8.2$ for Basque pigs.

\title{
Variation in the inbreeding coefficient within a small pig population : the Limousin breed
}

\section{H. DE ROCHAMBEAU}

I.N.R.A., Station d'Amélioration génétique des Animaux, B.P. 12, 31320 Castanet-Tolosan

\section{France}

Variation in the mean inbreeding coefficient and in the percentage of initial genes still present after 20 years was studied using simulation methods within small-sized pig populations. First, the population included 6 boars and 60 sows. Random matings were performed, the initial animals were neither inbred, nor related. After 20 years, the mean inbreeding coefficient was equal to $11.4 \mathrm{p}$. 100 and $80.5 \mathrm{p}$. 100 of the initial genes were "lost" due to genetic drift. The effect of variations in the number of males and females on these two factors was also studied (table 1). Then, we observed a population divided into 4 reproduction groups including 15 sows and 1 boar. Some aspects of boar management were tested (table 2 : use of frozen semen, accelerated turnover, accidental death of one boar). It was concluded that to reduce the loss of genetic variability it was necessary to increase the number of males and females actually mated each year, to constitute reproduction groups and to organize the boar circulation between these groups. 